\title{
Review Article \\ PPAR Ligands as Potential Modifiers of Breast Carcinoma Outcomes
}

\begin{abstract}
Ancha Baranova
Center for Biomedical Genomics and Bioinformatics, Molecular and Microbiology Department, College of Science, George Mason University, Fairfax, VA 22031, USA
\end{abstract}

Correspondence should be addressed to Ancha Baranova, abaranov@gmu.edu

Received 29 February 2008; Accepted 19 May 2008

Recommended by Dipak Panigrahy

Chemically synthesized ligands for nuclear receptors of the PPAR family modulate a number of physiological functions, particularly insulin resistance in the context of energy homeostasis and the metabolic syndrome. Additionally, these compounds may treat or prevent the development of many secondary consequences of the metabolic syndrome. Many PPAR agonists are also known to influence the proliferation and apoptosis of breast carcinoma cells though the experiments were carried out at suprapharmacological doses of PPAR ligands. It is possible that the breast epithelium of diabetics exposed to PPAR agonists will experience perturbation of the corresponding signaling pathway. Consequently, these patients' lifetime breast carcinoma risks could be modified, as their breast lesion incidence or the rates of the conversion of these lesions to carcinomas might vary upward or downward. PPAR activating treatment may also influence the progression of existing, undiagnosed invasive lesions. In this review, we attempt to summarize the possible influence of chemical PPAR ligands on the molecular pathways involved in the initiation and progression of breast carcinoma, with a major emphasis on PPAR $\gamma$ agonists thiazolidinediones (TZDs).

Copyright (c) 2008 Ancha Baranova. This is an open access article distributed under the Creative Commons Attribution License, which permits unrestricted use, distribution, and reproduction in any medium, provided the original work is properly cited.

\section{INTRODUCTION}

Breast carcinoma is the most common nonskin cancer among women worldwide, responsible for about 375000 deaths per year [1]. The probability of the development of breast carcinoma increases before menopause (ages 40-50) and then gradually decreases, possibly due to diminishing levels of circulating estrogens [2]. In developed countries, the prevalence of breast carcinoma is higher due to the frequency of known risk factors for the disease, including early age at menarche, nulliparity, late age at first birth, late menopause, and brief duration of breastfeeding [2]. All of these risk factors are tightly linked to hormonal background, particularly to lifelong exposure of breast tissue to endogenous estrogens [3]. Exogenous factors influencing breast carcinoma development include the use of oral contraceptives [4] and hormone replacement therapy [5, 6] as well as dietary or lifestyle-related variables. The latter category is rather vague, as it includes many factors detrimental to general health, such as high body-mass index [7], high fat intake [8], high red meat consumption [9], excessive alcohol consumption [10], and reduced physical activity [11].
A number of chemoprevention strategies for breast carcinoma are developed or under development. The noteworthy example is a tamoxifen chemoprevention in highrisk premenopausal women, which heralded the success of selective estrogen receptor modulators (SERMs) [12]. A new agent, raloxifene (Evista, Eli Lilly, IN, USA) also competes with endogenous estrogen for ER binding and shows similar promises with fewer side effects [13]. Interestingly, many potential breast carcinoma preventive agents studied earlier are also available over-the-counter and widely used by target populations. Examples of this kind include aspirin [14], soy isoflavones [15], and Vitamin D [16].

Recently, the universe of chemical compounds commonly encountered by current and future breast carcinoma patients has been enriched by a number of pharmacotherapeutic agents being prescribed as a lifelong support for common chronic diseases. Depending on the particular molecular pathways which these agents modulate, they may contribute to initial immortalization of breast epithelia, stimulate proliferation and invasion of existing tumor cells, or on the contrary, prevent the tumor's development. For example, type II diabetes patients are routinely treated with 
chemically synthesized ligands for $\operatorname{PPAR} \gamma$, thiazolidinedione (TZD), namely pioglitazone (Actos, Takeda/Lilly), and rosiglitazone (Avandia, GlaxoSmithKline). The glucoselowering effects of these compounds are mediated primarily by decreasing insulin resistance and increasing glucose uptake by the skeletal muscles [17]. In addition, TZDs suppress glucose production in the liver [17]. These and other beneficial effects rapidly made TZDs a mainstream diabetes therapy [18].

In addition to their antidiabetic effects, TZDs are known to suppress the proliferation and induce apoptosis of breast carcinoma cells in vitro $[19,20]$. It is likely that the breast epithelium of diabetics exposed to TZDs will also experience perturbation of the PPAR signaling pathway. Consequently, current or past TZD users' lifetime breast carcinoma risks may be modified, as their breast lesion incidence or rates of the conversion of these lesions to carcinomas might change upward or downward. TZD treatment may also influence the progression of existing undiagnosed invasive lesions.

In addition to PPAR $\gamma$ ligands, $\operatorname{PPAR} \alpha[21]$ and $\operatorname{PPAR} \delta$ [22] are currently being explored as potential cardiovascular therapeutics and metabolic syndrome alleviation agents. If these agents will be approved by FDA, it is very possible that in the next two or three decades the number of women exposed to one or another type of PPAR ligands may reach 10-15 million in the USA alone. Possible modifications of the breast carcinoma incidence and outcomes resulted by the chronic exposure to these compounds might translate into statistically significant changes visible in epidemiological survey data, similar to those seen in cohorts taking hormone replacement therapy $[5,6]$.

In this review, we attempt to summarize the possible influence of chemical PPAR ligands on the molecular pathways involved in the initiation and progression of breast carcinoma. Major emphasis will be on $\operatorname{PPAR} \gamma$, as small molecular agonists of this nuclear receptor are widely used in the treatment of type II diabetes all over the world.

\section{PPAR $\gamma$ LIGANDS}

A gene encoding nuclear hormone receptor, $\operatorname{PAAR} \gamma$, expresses as two different mRNA isoforms derived from the alternative promoters, ubiquitous $\operatorname{PPAR} \gamma 1$ and adiposespecific PPAR $\gamma 2$ [23]. Both isoforms stimulate adipogenesis; however, PPAR $\gamma 2$ can be activated by lower concentrations of ligands [23]. Activated PPAR $\gamma$ heterodimerizes with various coactivators $[24,25]$, which modulate the expression of genes with promoters containing bi-hexametric PPRE elements. These elements are widespread in the human genome, being present in both fatty acid metabolism and cell cycle control genes [26]. Moreover, the list of targets directly regulated by PPAR $\gamma$ includes many genes which lack PPRE [27]. Most likely, this is due to either the binding of activated PPAR $\gamma$ to other proteins that, in turn, serve as transcription factors (TFs) or the action of PPRE-containing genes providing delayed transcriptional response to PPAR $\gamma$ ligation [27]. Knowledge about endogenous ligands for PPAR $\gamma$ is limited. The list of these compounds includes polyunsaturated fatty acids (PUFAs) and eicosanoids, particularly lipoxygenase
(LOX), and cyclooxygenase (COX) products [28]. An antiinflammatory prostaglandin, 15-deoxy-D12,14-PGJ2 (15dPGJ2), which is formed from PGD2 in vivo, is probably the most potent endogenous PPAR $\gamma$ ligand [28]. Another powerful physiological stimulator of PPAR $\gamma$ is oxidized phosphatidylcholine [29]. It should be mentioned that synthetic ligands of PPAR $\gamma$ (TZDs) display stronger binding affinity to this nuclear receptor than its endogenous ligands, thus raising the question whether the list of natural PPAR $\gamma$ ligands is complete.

\subsection{Effects of the chronic exposure of the breast epithelium to PPAR y agonists}

PPAR $y$ is expressed in normal breast tissue and in many primary breast carcinoma specimens $[30,31]$. Comparative studies of PPAR $\gamma$ expression in breast carcinoma patients so far have produced contradictory results [32-34]. Described associations between PPARG polymorphisms and breast carcinoma are also discrepant: some researchers see a marginally significant increase in the risk of breast cancer among women homozygous for the Ala allele of PPAR $\gamma$ (Pro12Ala), causing a reduction in the transcriptional activity of PPAR $\gamma 2$ [35], while others stress that carriers of the same variant allele are at lower risk [36]. Since complete loss of PPAR $y$ signaling in clinical breast tumors seems to be a rare event [37], it is likely that patients undergoing chronic treatment with chemical ligands for PPAR $\gamma$ will experience alteration in the behavior of both breast carcinoma cells and their normal counterparts. Patients with ER-positive tumors might benefit from TZD exposure more than those with ER-negative tumors, as the level of PPAR $\gamma$ expression is significantly associated with the ER status of carcinoma cells [38].

Chemically synthesized ligands for PPAR $\gamma$ (thiazolidinediones, or TZDs) have actively been used as insulin sensitizers since the late 90s [18]. In addition to their insulin resistance-alleviating effects, TZDs may influence an incidence or a progression of breast carcinoma lesions as they have been shown to suppress the proliferation rates of many types of cancer cells and induce either their differentiation or apoptosis in vitro $[20,39,40]$. Responsiveness to TZDs has been demonstrated for both normal human mammary epithelial cells [30] and breast cancer cells [41-43], although it was not uniformly seen in all experimental conditions [44]. TZDs suppress the cell cycle by repressing cyclins D1 and D3 [45], by stimulating expression of the tumor suppressor p53 and its effector p21 (WAF1/Cip1) [46], and by inhibiting the Akt/PTEN pathway [47]. Additionally, TZDs induce marked cellular acidosis in breast carcinoma cell lines, leading to a decrease in the number of viable cells [48]. Some effects of TZDs are independent of the transcriptional activities of PPAR $\gamma$ [48]; these effects may be mediated through interactions of these compounds with other cellular targets.

The growth-suppressive properties of TZDs are complemented by their ability to induce apoptosis. Many breast tumors are naturally resistant to the apoptotic action of the tumor necrosis factor-related apoptosis-inducing ligand (TRAIL) and other similar agents. TZDs sensitize these cells to TRAIL [45], to anti-Fas $\operatorname{IgM}(\mathrm{CH} 11)$, and to tumor 
necrosis factor (TNF)- $\alpha$ [49]. It is tempting to speculate that TZDs might prevent the spread of microscopic breast tumors by sensitizing malignant cells to these endogenous apoptotic signals. Interestingly, TZDs also synergize with alltrans-retinoic acid (ATRA) to induce apoptosis in MCF-7 and primary breast carcinoma cells, but not in the normal breast epithelium [43]. Some TZDs also stimulate expression of apoptosis related genes, such as growth arrest and DNA damage-inducible gene 45 (GADD45) [50], BRCA1 [51] and proline oxidase encoding gene POX [52]. In addition to intrinsic apoptotic pathways, TZDs are also capable of the direct stimulation of the FASL gene encoding Fas ligand that induces an apoptosis by cross-linking with the Fas receptor located on the membranes of the adjacent cells [53].

Additionally, TZDs block the invasion of tumor cells through upregulation of the tissue inhibitor of MMP1/TIMP-1 and a subsequent decrease in MMP-9 gelatinolytic activities [54]. These observations have been supported by experiments with the murine mammary tumor cell line LMM3, which produces less metastatic nodules in lungs of animals treated by oral rosiglitazone [55]. It should be mentioned that the pronounced antitumor effects described above occur only at suprapharmacological doses of TZDs. It remains to be seen whether chronic exposure to TZDs could have therapeutic effects in patients with established breast tumors.

The effects described above are relevant only to some TZD users, namely, patients currently with breast tumors and those diagnosed with such tumors in the past. It is still unclear whether action of PPAR $\gamma$ ligands is different within normal and tumor cells, and what would be effects of TXD exposure in cancer free individuals. There are some indications that PPAR $y$ ligands may influence the initial stages of breast carcinoma development, in particular, immortalization of the breast epithelia. One recent study demonstrated that exposure to low nontoxic doses of rosiglitazone (10 nM) reduces the frequency of spontaneous immortalization of Li-Fraumeni syndrome (LFS)-derived ( $\mathrm{p} 53+/-$, telomerase silent) breast epithelial cells by almost four times [56]. In these experimental settings, the antimutagenic properties of this widely prescribed TZD were superior to those of wellknown chemopreventive agents such as sulindac sulfide and celecoxib [56]. It will be interesting to see whether exposure to TZD is capable of lowering the incidence of malignant foci in the breast epithelia genetically predisposed to breast carcinoma development, particularly that of carriers of mutations in BRCA, BRCA2, or ATM.

Some effects outlined above result from the interference of PPAR $y$ signaling with other pathways involved in breast carcinogenesis, particularly with estrogen receptor (ER) $\alpha$ and NF- $\kappa \mathrm{B}$ cascades. Agonists of PPAR $\gamma$ may suppress $\mathrm{NF}-\kappa \mathrm{B}$ dependent transcription either through an increase in physical interaction between PPAR $y$ and p65 [57] or through SUMOylation-dependent targeting of PPAR $y$ to NCoR/histone deacetylase-3 (HDAC3) corepressor complexes which prevent NCoR/HDAC3 clearance from NF- $\kappa \mathrm{B}$ target gene promoters [58]. The interplay between ER and PPAR $y$ signaling seems to be more complex. Many PPAR $\gamma$ ligands, particularly troglitazone and ciglitazone, inhibit ER $\alpha$ signaling by stimulating proteasomal degradation of ER $\alpha$ [59].

On the other hand, one recent study's findings are disturbing: in the breast cancer cell line MCF-7, commonly used as a model for ER-positive breast carcinoma, TZD rosiglitazone has been shown to induce both estrogen receptor response element activity and cell proliferation [44]. Even more disturbing is the fact that in dose-response assays higher concentrations of rosiglitazone inhibited proliferation, while lower concentrations of the same compound induced proliferation. Rosiglitazone-induced proliferation and ERE reporter activation were mediated by $\operatorname{ER} \alpha$ and the extracellular signal-regulated kinase-mitogen activated protein kinase (ERK-MAPK) pathway [44]. The concentrationdependent nature of rosiglitazone's effects may have tremendous clinical importance for the chronic users of TZDs. Moreover, these findings point at the possibility that the effects of the rosiglitazone might vary between individuals, as the bioavailability of rosiglitazone depends on the activity of the CYP2C9 and CYP2C8 enzymes [60], which are substantially polymorphic in human populations.

\subsection{Chronic exposure to PPAR $\gamma$ agonists influences nonepithelial cells participating in breast carcinoma development}

In addition to the effects of PPAR $y$ ligands on premalignant and malignant breast epithelia, these compounds also produce profound changes in noncancerous cells. Some of these changes may be relevant to breast carcinoma outcomes. For example, PPAR $y$ ligands demonstrate antiangiogenic effects (reviewed in [40]), including direct suppression of the vascular endothelial growth factor (VEGF) and the angiopoietin-1 (Ang-1) gene transcription [61, 62]. On the other hand, in some noncancerous settings, PPAR $\gamma$ ligands stimulate angiogenesis $[63,64]$, thus pointing to their involvement in remodeling tumor vessels rather than in suppressing angiogenesis per se.

In vitro experiments suggest that PPAR $\gamma$ ligands act as differentiating agents in nonmalignant stromal cells. Malignant epithelialcells of breast tumors secrete growth factors and cytokines to prevent the differentiation of periand intratumoral stromal fibroblasts into mature adipocytes by downregulation of adipogenic factors such as the $\mathrm{C} / \mathrm{EBP} \alpha$ and $\operatorname{PPAR} \gamma$ [65]. In turn, underdifferentiated fibroblasts provide structural and secretory growth promoting support to tumor tissue [66]. Prolonged treatment with TZDs stimulates the differentiation of fibroblasts into adipocytes instead of myofibroblasts and interferes with transforming growth factor beta (TGF $\beta$ ) fibrogenic pathway, particularly, through attenuation of TGF $\beta$-driven type I collagen protein production [67]. Taken together, these effects of TZDs may to some degree counteract desmoplastic proliferative response promoted by tumor proximity and delay the formation of the scirrhous component of the breast tumors and the subsequent spread of tumor cells.

It must be taken into account that an interference of TZDs with TGF $\beta$ signaling is a double-edged sword, since TGF $\beta$ serves as both a tumor suppressor and a tumor 
promoter depending on tumor developmental stages and cellular context [19]. During the initial phase of breast tumorigenesis, the TGF $\beta$ signal inhibits primary tumor development and growth by constraining cell division and possibly inducing apoptosis [68, 69]. In the later stages of breast carcinoma development, tumors lose their sensitivity to $\operatorname{TGF} \beta$, but continue overproduction of the hormone. Excess TGF $\beta$ acts upon stromal components of the tumor promoting the metastatic process through desmoplastic reaction, inhibiting host immune surveillance, and stimulating invasion and angiogenesis [70]. The outcome of the crosstalk between TGF $\beta$ and PPAR $\gamma$ in breast carcinoma patients should be dependent on stage of the particular breast lesion.

Last but not least, TZD therapy has been shown to produce an average weight gain of $4-5 \mathrm{~kg}$, which cannot be explained by fluid retention [71]. The magnitude of weight gain correlates in part with improved metabolic control, that is, better responders are more prone to increases in body weight [72]. In turn, weight gain is associated with a significant increase in postmenopausal ER-positive/PRpositive breast cancer $[73,74]$. It remains to be seen whether TZD-associated increases in adiposity contribute to breast carcinoma risks similarly to nonspecific weight gain.

\subsection{Effects of TZDs on breast carcinogenesis in vivo}

The PPAR $y$ agonist GW7845 delays the development of mammary tumors in immunocompetent mice treated with medroxyprogesterone acetate followed by DMBA administration by an average of 2 months [75]. In the classic rat model of mammary tumorigenesis employing nitrosomethylurea as a carcinogen, GW7845 also significantly reduces both tumor incidence and tumor weight [76]. Similarly, troglitazone, alone or in combination with RXR ligands, prevents the induction of preneoplastic lesions in a mouse mammary gland organ culture model treated by DMBA [77]. TZD treatment alone or in combination with ATRA suppresses tumor growth from breast carcinoma cells MCF-7 [43]. On the other hand, attempted rosiglitazone chemoprevention of breast carcinogenesis in the MMTV-HER-2/neu transgenic mouse model produced no encouraging data [78]. It is important to note that the mechanisms underlying various routes of the tumorigenesis in rodent breast differ substantially [79]; therefore, it is entirely possible that TZDs may modify outcomes only in some of the models studied. It is also possible that these effects might be either compound or dose-specific.

Recently, a few epidemiological studies have explored the association of TZD-based diabetes therapy and breast carcinoma incidence. The largest profiled cohort was the one covered by the Integrated Healthcare Information Services (IHCISs), Mass, USA, managed care database [80]. The relevant part of IHCIS allowed analysis of pharmacy and doctor's office claim data related to 126971 nonelderly USA diabetics with a mean followup time of 16.6 months. Importantly, each individual case of breast carcinoma $(N=513)$ was matched to up to five diabetes controls (cumulative $N=2557$ ) using matched nested case-control design. The adjusted odds ratios and 95\% CI for breast cancer from any exposure to TZD (mono- or combination therapy) compared to all non-TZD antidiabetic agents were $0.89(0.68-1.15)$ [80]. Thus, neither a beneficial nor a deleterious effect of TZDs on the likelihood of breast carcinoma development was found. It should be mentioned that the median duration of followup in the studied cohort was rather short for the development of breast tumors. Studies following patients for longer periods of time are warranted.

Another group of researchers analyzed 1003 adult diabetic patients participating in a Vermont Diabetes Information System (VDIS) study and revealed a significant association between any cancer and the use of any TZD $(\mathrm{OR}=1.59,95 \% \mathrm{CI}(1.03-2.44), P=.04)$ [79]. When TZDs were analyzed by compound, a significant association was found for rosiglitazone (OR $=1.89$, 95\% CI (1.113.19), $P=.02$ ), but not for pioglitazone. Stratification by gender showed a highly significant association between cancer prevalence and TZD use for women $(\mathrm{OR}=2.07$, 95\% CI (1.18-3.63), $P=.01$ ) [81], but not for men. It is important to note that the number of the patients enrolled in this study is not allowed assessment of the risks for individual cancers. Nevertheless, the increase of tumor incidence in TZD using women points at the possible vulnerability of the breast epithelia.

Slightly more encouraging results were produced in the recently completed PROactive Study (PROspective pioglitAzone Clinical Trial In macroVascular Events). This study reviewed longitudinal data of 5238 diabetic patients treated with pioglitazone or with a placebo [82]. The incidence of breast carcinoma was nonsignificantly reduced in the pioglitazone-treated group ( 3 versus 11 cases in the equally sized pioglitazone and placebo arms of the study, resp.).

Several attempts to use TZDs as a means of therapy for breast carcinoma have been made so far. One trial of TZD as a monotherapy ended 5 months after it started, because troglitazone was withdrawn from the marker. This trial-performed in the cohort of patients with advanced breast cancer refractory to at least one chemotherapy regimen-resulted in no objective responses [83]. Another attempt at TZD monotherapy enrolled 38 women with early-stage lymph node negative breast carcinomas. This intervention was even shorter as rosiglitazone treatment $(8 \mathrm{mg} / \mathrm{d})$ was given between the time of diagnostic biopsy and definitive surgery. No significant effects on breast tumor cell proliferation were observed using Ki67 expression as an endpoint. Interestingly, rosiglitazone treatment leads to down-regulation of nuclear PPAR $y$ expression, as demonstrated by immunohistochemistry. Additionally, rosiglitazone intervention resulted in an increase of serum adiponectin concentrations $(P<.001)$. Serum adiponectin negatively regulates breast cancer growth [84] and inhibits angiogenesis by suppression of endothelial cell proliferation and migration [85]. The potential therapeutic implications of rosiglitazone modulation of adiponectin levels require further study.

\section{3. $\operatorname{PPAR} \alpha$ LIGANDS}

The nuclear receptor PPAR $\alpha$ regulates lipid metabolism in general and $\beta$-oxidation of fatty acids in particular. 
Its gene, $P P A R A$, expresses mainly in tissues with high energy requirements, particularly in the skeletal muscle, the heart, and the liver [86]. PPAR $\alpha$ is activated by a number of natural ligands, including various derivatives of fatty acids and leukotriene B4, and by common lipid-lowering drugs, particularly fenofibrate and gemfibrozil. Activated $\operatorname{PPAR} \alpha$ exerts beneficial effects on lipid metabolism, raising cardioprotective high-density lipoprotein (HDL) cholesterol and lowering cardiovascular mortality [87]. In addition, activation of PPAR $\alpha$ may limit inflammation, both in the vessel endothelium and in other tissues as well as inhibit the fibrotic response. The apparent uniformly beneficial action of PPAR $\alpha$ agonists prompted the development of a number of these compounds. Among them, some exert dual affinity to $\operatorname{PPAR} \alpha$ and $\operatorname{PPAR} \gamma$. Dual agonists hold considerable promise in the management of insulin resistance, serving as major confounders for cardiovascular diseases and other comorbidities associated with metabolic syndrome.

Experimental data describing the effects of PPAR $\alpha$ agonists on tumor initiation and progression are limited. Longterm administration of PPAR $\alpha$ ligands clofibrate and WY14643 in the rodent model induces hepatocellular neoplasms including adenomas and carcinomas [88]. PPAR $\alpha$ suppresses apoptosis in liver tissue in response to various peroxisome proliferator carcinogens, especially in the presence of TNF $\alpha$ [89]. As levels of TNF $\alpha$ are substantially elevated in obesity and in metabolic syndrome, it could be hypothesized that hepatocarcinogenesis may be an issue for long-term fibrate medicated patients. So far, epidemiological observations in fibrate treated populations have not produced any evidence that fibrates are associated with elevated risk of liver cancer or any other neoplasms in humans. As PPAR $\alpha$-humanized mice are resistant to hepatocarcinogenic effects of fibrates, it seems that the response described in mouse models is species specific [90].

Studies of the nonhepatic tumorigenesis models indicate that in other tissues PPAR $\alpha$ agonists exert antiproliferative effects [91]. In the mouse model of skin carcinogenesis, an animal topically treated with $\operatorname{PPAR} \alpha$ ligands exhibited an approximately 30\% lower skin tumor yield compared with mice treated with vehicle, thus indicating that the activation of PPAR $\alpha$ may suppress the earliest stages of tumor development [92]. Additionally, $\operatorname{PPAR} \alpha$ ligands possess strong antiangiogenic properties, as they suppress endothelial cell proliferation and VEGF production, upregulate TSP-1 and endostatin, and inhibit neovascularization [93, 94].

Studies concerning PPAR $\alpha$ activation in breast carcinomas are scarce. It is known that PPAR $\alpha$ is expressed and dynamically regulated in both ER-positive (MCF-7) and ERnegative (MDA-MB-231) human breast cancer cells. PPAR $\alpha$ activation significantly increases proliferation of both cell lines, and this increase is proportional to the endogenous level of PPAR $\alpha$ [95]. On the other hand, one recent study pointed at $\operatorname{PPAR} \alpha$ as a possible contributor to the growth inhibitory effect of n-6 PUFA arachidonic acid exerted in the same pair of breast carcinomas cell lines [96].

$\operatorname{PPAR} \alpha$ also reduces the sensitivity of MCF-7cells to histone deacetylase inhibitors [97]. Interestingly, there is an inverse relationship between mean $\operatorname{PPAR} \alpha$ and $\operatorname{ER} \alpha$
mRNA levels in ER-positive breast cancer cells [97]. These observations point to the possible involvement of PPAR $\alpha$ activation in mammary gland tumorigenesis and vouch for a longitudinal study of breast carcinoma incidence and progression in patients using fibrate therapy.

\section{PPAR $\delta$ LIGANDS}

The nuclear receptor $\operatorname{PPAR} \delta$, also known as $\operatorname{PPAR} \beta$, is expressed ubiquitously. It controls a number of physiological functions, particularly cell proliferation and differentiation as well as inflammation and energy homeostasis [22]. Interestingly, PPAR $\delta$ is the only PPAR isoform that maintains repressor activity when bound to DNA. When unligated, $\operatorname{PPAR} \delta$ can act as an intrinsic transcription repressor and inhibit the trans-activation activity of other PPARs [98]. It was suggested that $\operatorname{PPAR} \delta$ serves as a gateway receptor capable of modulating $\operatorname{PPAR} \alpha$ and PPAR $\gamma$ activity [98]. The ligand binding pocket domain of $\operatorname{PPAR} \delta$ is larger than that of other PPARs and is believed to accommodate the binding of various fatty acids and their derivatives [99]. A number of synthetic agonists are being developed for the same purpose with nanomolar affinities $[100,101]$, although none is currently marketed for clinical use in humans yet.

The physiological effects of activated PPAR $\delta$ have been studied extensively $[22,102]$. The results of these studies suggest that sooner or later high-affinity $\operatorname{PPAR} \delta$ synthetic drugs which uniquely target multiple components of the metabolic syndrome, including obesity, insulin resistance, hyperglycemia, dyslipidemia, and atherosclerosis will enter the market. Some of these compounds are already being subjected to phase I/II clinical trials. In light of this fact, it is important to establish experimental systems allowing rapid evaluation of the potential carcinogenic or chemopreventive effects of the synthetic PPAR $\delta$ ligands. Given that the prevalence of the metabolic syndrome and comorbidities associated with the disease is on the rise in both developed and developing countries, it is extremely important to watch for possible effects of anticipated chronic exposure to PPAR $\delta$ ligands upon common types of cancer, particularly upon breast carcinoma.

Alarmingly, $\operatorname{PPAR} \delta$ selective agonists stimulate the growth of the hormone-dependent breast carcinoma cell lines T47D and MCF-7. In T47D cells, activation of PPAR $\delta$ stimulates expression of the proliferation marker Cdk2. In addition, an increase in the production of both VEGF and its receptor, FLT- 1 has been noted, suggesting that PPAR $\delta$ may initiate an autocrine loop for cellular proliferation and possibly angiogenesis. Similar pro-proliferative effects of activated PPAR $\delta$ have been observed in endothelial cell cultures [103]. Further studies of angiogenic and growthinducing properties of $\operatorname{PPAR} \delta$ agonists in breast epithelia are warranted.

\section{GENERAL REMARKS}

It should be mentioned that breast carcinoma is not a single disease entity, but rather an extremely polymorphic spectrum of neoplastic pathologies which are fairly diverse in 


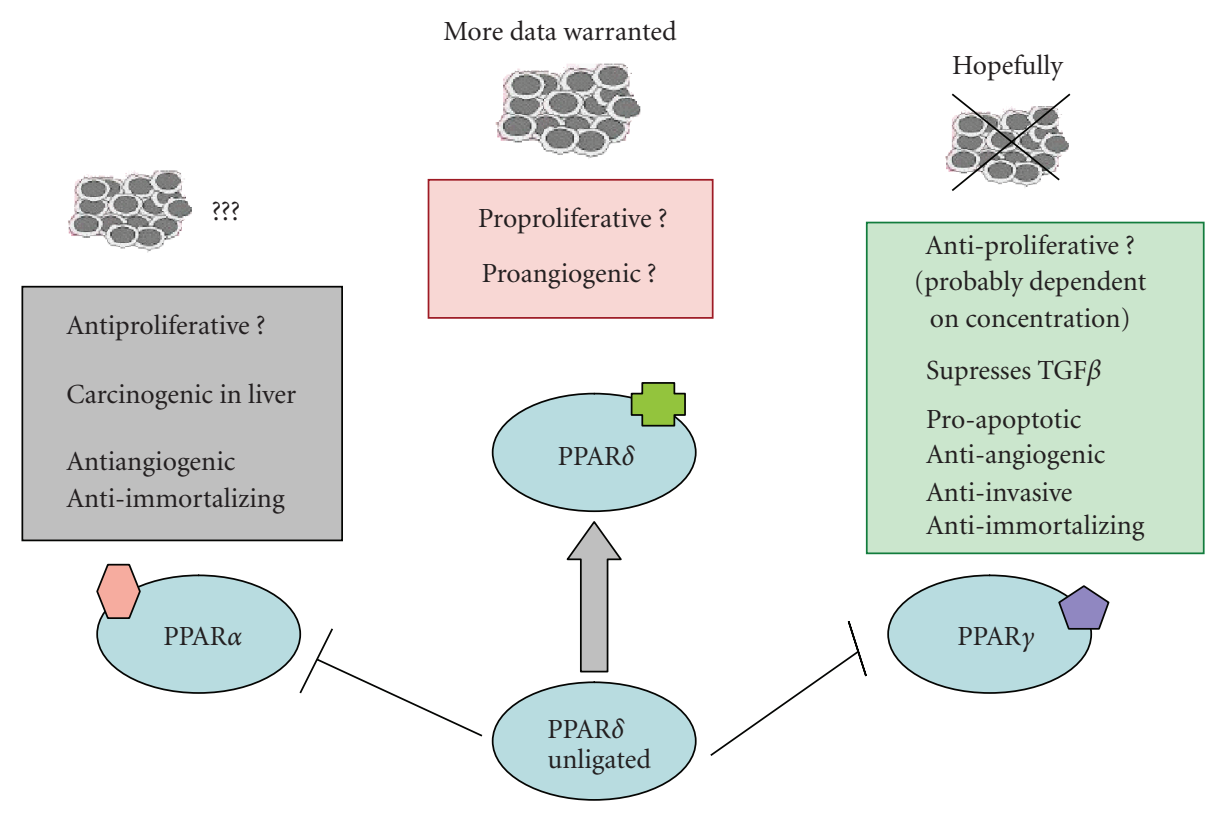

FIgURE 1: A summary of influence of PPAR ligands on the process of breast carcinogenesis.

their molecular portraits. It is likely that both chemoprevention and treatment by PPAR ligands as well as their possible tumorigenic side effects will be selective to particular molecular subtypes of tumor, or will be relevant to certain stages of carcinoma progression (Figure 1). Therefore, much larger cohorts of patients followed for longer periods of time will have to be studied in order to reveal statistically significant modifications of the disease's outcome. Chemoprevention studies of this type are prohibitively expensive, for example, the recently completed National Surgical Adjuvant Breast and Bowel Project Study of Tamoxifen and Raloxifene (STAR) trial with an endpoint of cancer incidence required the enrollment of 19747 subjects from near 200 clinical centers throughout North America took 8 years before initial data analysis, and cost approximately \$200 million [104, 105]. Before initiating large-scale efforts, a comparative study of the molecular portraits of breast carcinomas developed in chronic TZD users and in the general population needs to be completed. This kind of study could be performed using microarrays as a primary profiling means which should be complemented by validation efforts through the methods of immunohistochemistry, in situ hybridization of mRNA, and phosphoproteomics. The design of this study could be a challenge due to the difficulties with proper matching of groups compared and with eliminating common confounders. One of the possible ways to overcome this problem is to profile both malignant and normal breast epithelia samples of current TZD users to that of recently diagnosed diabetics never exposed to TZDs. Confirmed differences between the molecular portraits of tumors which initiated or progressed despite an exposure to PPAR ligand and subtype-matched tumors that arose on TZD free background may give some important clues to the design of a clinical trial aimed at chemoprevention-related endpoints.

\section{ACKNOWLEDGMENTS}

This work was supported by Susan G. Komen Grant no. BCTR0600525 "Molecular Network Profiling of DCIS for Patient Stratification and Individualized Therapy" and by NIH R15CA113331-01. Author is grateful to all INOVA Health System clinicians and staff members participating in long-term collaboration with GMU.

\section{REFERENCES}

[1] J. Ferlay, F. Bray, P. Pisani, and D. M. Parkin, GLOBOCAN 2000: Cancer Incidence, Mortality and Prevalence Worldwide, Version 1.0, IARC Cancer Base no. 5, IARC Press, Lyon, France, 2001.

[2] F. Bray, P. McCarron, and D. M. Parkin, "The changing global patterns of female breast cancer incidence and mortality," Breast Cancer Research, vol. 6, no. 6, pp. 229-239, 2004.

[3] M. C. Pike, M. D. Krailo, B. E. Henderson, J. T. Casagrande, and D. G. Hoel, "'Hormonal' risk factors, 'breast tissue age' and the age-incidence of breast cancer," Nature, vol. 303, no. 5920, pp. 767-770, 1983.

[4] Collaborative Group on Hormonal Factors in Breast Cancer, "Breast cancer and hormonal contraceptives: collaborative reanalysis of individual data on 53297 women with breast cancer and 100239 women without breast cancer from 54 epidemiological studies," The Lancet, vol. 347, no. 9017, pp. 1713-1727, 1996.

[5] C. Stahlberg, A. T. Pedersen, E. Lynge, et al., "Increased risk of breast cancer following different regimens of hormone replacement therapy frequently used in Europe," International Journal of Cancer, vol. 109, no. 5, pp. 721-727, 2004.

[6] A. Fournier, F. Berrino, E. Riboli, V. Avenel, and F. ClavelChapelon, "Breast cancer risk in relation to different types of hormone replacement therapy in the E3N-EPIC cohort," 
International Journal of Cancer, vol. 114, no. 3, pp. 448-454, 2005.

[7] J. Ahn, A. Schatzkin, J. V. Lacey Jr., et al., "Adiposity, adult weight change, and postmenopausal breast cancer risk," Archives of Internal Medicine, vol. 167, no. 19, pp. 2091-2102, 2007.

[8] E. Cho, D. Spiegelman, D. J. Hunter, et al., "Premenopausal fat intake and risk of breast cancer," Journal of the National Cancer Institute, vol. 95, no. 14, pp. 1079-1085, 2003.

[9] E. Cho, W. Y. Chen, D. J. Hunter, et al., "Red meat intake and risk of breast cancer among premenopausal women," Archives of Internal Medicine, vol. 166, no. 20, pp. 2253-2259, 2006.

[10] R. Suzuki, W. Ye, T. Rylander-Rudqvist, S. Saji, G. A. Colditz, and A. Wolk, "Alcohol and postmenopausal breast cancer risk defined by estrogen and progesterone receptor status: a prospective cohort study," Journal of the National Cancer Institute, vol. 97, no. 21, pp. 1601-1608, 2005.

[11] J. Verloop, M. A. Rookus, K. D. van der Kooy, and F. E. van Leeuwen, "Physical activity and breast cancer risk in women aged 20-54 years," Journal of the National Cancer Institute, vol. 92, no. 2, pp. 128-135, 2000.

[12] V. C. Jordan, "Chemoprevention of breast cancer with selective oestrogen-receptor modulators," Nature Reviews Cancer, vol. 7, no. 1, pp. 46-53, 2007.

[13] B. A. Geller and V. G. Vogel, "Chemoprevention of breast cancer in postmenopausal women," Breast Disease, vol. 24, no. 1, pp. 79-92, 2005.

[14] S. Mangiapane, M. Blettner, and P. Schlattmann, "Aspirin use and breast cancer risk: a meta-analysis and metaregression of observational studies from 2001 to 2005," Pharmacoepidemiology and Drug Safety, vol. 17, no. 2, pp. 115-124, 2008.

[15] N. B. Kumar, A. Cantor, K. Allen, D. Riccardi, and C. E. Cox, "The specific role of isoflavones on estrogen metabolism in premenopausal women," Cancer, vol. 94, no. 4, pp. 1166 $1174,2002$.

[16] E. R. Bertone-Johnson, "Prospective studies of dietary vitamin $\mathrm{D}$ and breast cancer: more questions raised than answered," Nutrition Reviews, vol. 65, no. 10, pp. 459-466, 2007.

[17] V. Bhatia and P. Viswanathan, "Insulin resistance and PPAR insulin sensitizers," Current Opinion in Investigational Drugs, vol. 7, no. 10, pp. 891-897, 2006.

[18] R. J. Durbin, "Thiazolidinedione therapy in the prevention/delay of type 2 diabetes in patients with impaired glucose tolerance and insulin resistance," Diabetes, Obesity and Metabolism, vol. 6, no. 4, pp. 280-285, 2004.

[19] M. H. Jarrar and A. Baranova, "PPAR $\gamma$ activation by thiazolidinediones (TZDs) may modulate breast carcinoma outcome: the importance of interplay with TGF $\beta$ signalling," Journal of Cellular and Molecular Medicine, vol. 11, no. 1, pp. 71-87, 2007.

[20] M. H. Fenner and E. Elstner, "Peroxisome proliferatoractivated receptor- $\gamma$ ligands for the treatment of breast cancer," Expert Opinion on Investigational Drugs, vol. 14, no. 6, pp. 557-568, 2005.

[21] F. Zandbergen and J. Plutzky, "PPAR $\alpha$ in atherosclerosis and inflammation," Biochimica et Biophysica Acta, vol. 1771, no. 8, pp. 972-982, 2007.

[22] G. D. Barish, V. A. Narkar, and R. M. Evans, "PPAR $\delta$ : a dagger in the heart of the metabolic syndrome," The Journal of Clinical Investigation, vol. 116, no. 3, pp. 590-597, 2006.
[23] L. Fajas, D. Auboeuf, E. Raspé, et al., "The organization, promoter analysis, and expression of the human PPAR $\gamma$ gene," Journal of Biological Chemistry, vol. 272, no. 30, pp. 18779-18789, 1997.

[24] H. Oberkofler, H. Esterbauer, V. Linnemayr, A. D. Strosberg, F. Krempler, and W. Patsch, "Peroxisome proliferatoractivated receptor (PPAR) $\gamma$ coactivator-1 recruitment regulates PPAR subtype specificity," Journal of Biological Chemistry, vol. 277, no. 19, pp. 16750-16757, 2002.

[25] J. E. Leader, C. Wang, M. Fu, and R. G. Pestell, "Epigenetic regulation of nuclear steroid receptors," Biochemical Pharmacology, vol. 72, no. 11, pp. 1589-1596, 2006.

[26] D. G. Lemay and D. H. Hwang, "Genome-wide identification of peroxisome proliferator response elements using integrated computational genomics," Journal of Lipid Research, vol. 47, no. 7, pp. 1583-1587, 2006.

[27] J. Hong, I. Samudio, S. Liu, M. Abdelrahim, and S. Safe, "Peroxisome proliferator-activated receptor $\gamma$-dependent activation of p21 in Panc-28 pancreatic cancer cells involves Sp1 and Sp4 proteins," Endocrinology, vol. 145, no. 12, pp. 5774 $5785,2004$.

[28] O. Nosjean and J. A. Boutin, "Natural ligands of PPAR $\gamma$ : are prostaglandin $\mathrm{J}_{2}$ derivatives really playing the part?" Cellular Signalling, vol. 14, no. 7, pp. 573-583, 2002.

[29] S. S. Davies, A. V. Pontsler, G. K. Marathe, et al., "Oxidized alkyl phospholipids are specific, high affinity peroxisome proliferator-activated receptor $\gamma$ ligands and agonists," Journal of Biological Chemistry, vol. 276, no. 19, pp. 16015-16023, 2001.

[30] L. D. Yee, Y. Guo, J. Bradbury, S. Suster, S. K. Clinton, and V. L. Seewaldt, "The antiproliferative effects of PPAR $\gamma$ ligands in normal human mammary epithelial cells," Breast Cancer Research and Treatment, vol. 78, no. 2, pp. 179-192, 2003.

[31] I. Papadaki, E. Mylona, I. Giannopoulou, S. Markaki, A. Keramopoulos, and L. Nakopoulou, "PPAR $\gamma$ expression in breast cancer: clinical value and correlation with ER $\beta$," Histopathology, vol. 46, no. 1, pp. 37-42, 2005.

[32] A. F. Badawi and M. Z. Badr, "Expression of cyclooxygenase2 and peroxisome proliferator-activated receptor- $\gamma$ and levels of prostaglandin $\mathrm{E}_{2}$ and 15-deoxy- $\Delta^{12,14}$-prostaglandin $\mathrm{J}_{2}$ in human breast cancer and metastasis," International Journal of Cancer, vol. 103, no. 1, pp. 84-90, 2003.

[33] G. Watkins, A. Douglas-Jones, R. E. Mansel, and W. G. Jiang, "The localisation and reduction of nuclear staining of PPAR $\gamma$ and PGC-1 in human breast cancer," Oncology Reports, vol. 12, no. 2, pp. 483-488, 2004.

[34] W. G. Jiang, A. Douglas-Jones, and R. E. Mansel, "Expression of peroxisome-proliferator activated receptor-gamma $(\operatorname{PPAR} \gamma)$ and the PPAR $\gamma$ co-activator, PGC-1, in human breast cancer correlates with clinical outcomes," International Journal of Cancer, vol. 106, no. 5, pp. 752-757, 2003.

[35] Y. Wang, M. L. McCullough, V. L. Stevens, et al., "Nested case-control study of energy regulation candidate gene single nucleotide polymorphisms and breast cancer," Anticancer Research, vol. 27, no. 1B, pp. 589-593, 2007.

[36] U. Vogel, J. Christensen, B. A. Nexø, H. Wallin, S. Friis, and A. Tjønneland, "Peroxisome profilerator-activated receptor $\gamma 2$ Pro $^{12}$ Ala, interaction with alcohol intake and NSAID use, in relation to risk of breast cancer in a prospective study of Danes," Carcinogenesis, vol. 28, no. 2, pp. 427-434, 2007.

[37] T. Ikezoe, C. W. Miller, S. Kawano, et al., "Mutational analysis of the peroxisome proliferator-activated receptor $\gamma$ gene in human malignancies," Cancer Research, vol. 61, no. 13, pp. 5307-5310, 2001. 
[38] T. Suzuki, S. Hayashi, Y. Miki, et al., "Peroxisome proliferator-activated receptor $\gamma$ in human breast carcinoma: a modulator of estrogenic actions," Endocrine-Related Cancer, vol. 13, no. 1, pp. 233-250, 2006.

[39] J.-R. Weng, C.-Y. Chen, J. J. Pinzone, M. D. Ringel, and C.S. Chen, "Beyond peroxisome proliferator-activated receptor $\gamma$ signaling: the multi-facets of the antitumor effect of thiazolidinediones," Endocrine-Related Cancer, vol. 13, no. 2, pp. 401-413, 2006.

[40] D. Panigrahy, S. Huang, M. W. Kieran, and A. Kaipainen, "PPAR $y$ as a therapeutic target for tumor angiogenesis and metastasis," Cancer Biology and Therapy, vol. 4, no. 7, pp. 687-693, 2005.

[41] E. Mueller, P. Sarraf, P. Tontonoz, et al., "Terminal differentiation of human breast cancer through PPAR $\gamma$," Molecular Cell, vol. 1, no. 3, pp. 465-470, 1998.

[42] F. Yin, S. Wakino, Z. Liu, et al., "Troglitazone inhibits growth of MCF-7 breast carcinoma cells by targeting G1 cell cycle regulators," Biochemical and Biophysical Research Communications, vol. 286, no. 5, pp. 916-922, 2001.

[43] E. Elstner, C. Müller, K. Koshizuka, et al., "Ligands for peroxisome proliferator-activated receptory and retinoic acid receptor inhibit growth and induce apoptosis of human breast cancer cells in vitro and in BNX mice," Proceedings of the National Academy of Sciences of the United States of America, vol. 95, no. 15, pp. 8806-8811, 1998.

[44] D. R. Talbert, C. D. Allred, Y. Y. Zaytseva, and M. W. Kilgore, "Transactivation of $\mathrm{ER} \alpha$ by rosiglitazone induces proliferation in breast cancer cells," Breast Cancer Research and Treatment, vol. 108, no. 1, pp. 23-33, 2008.

[45] M. Lu, T. Kwan, C. Yu, et al., "Peroxisome proliferatoractivated receptor $\gamma$ agonists promote TRAIL-induced apoptosis by reducing survivin levels via cyclin D3 repression and cell cycle arrest," Journal of Biological Chemistry, vol. 280, no. 8, pp. 6742-6751, 2005.

[46] D. Bonofiglio, S. Aquila, S. Catalano, et al., "Peroxisome proliferator-activated receptor- $\gamma$ activates $\mathrm{p} 53$ gene promoter binding to the nuclear factor- $\kappa \mathrm{B}$ sequence in human MCF7 breast cancer cells," Molecular Endocrinology, vol. 20, no. 12, pp. 3083-3092, 2006.

[47] L. Patel, I. Pass, P. Coxon, C. P. Downes, S. A. Smith, and C. H. Macphee, "Tumor suppressor and anti-inflammatory actions of PPAR $y$ agonists are mediated via upregulation of PTEN," Current Biology, vol. 11, no. 10, pp. 764-768, 2001.

[48] F. Turturro, E. Friday, R. Fowler, D. Surie, and T. Welbourne, "Troglitazone acts on cellular $\mathrm{pH}$ and DNA synthesis through a peroxisome proliferator-activated receptor $\gamma$-independent mechanism in breast cancer-derived cell lines," Clinical Cancer Research, vol. 10, no. 20, pp. 7022-7030, 2004.

[49] M. Mody, N. Dharker, M. Bloomston, et al., "Rosiglitazone sensitizes MDA-MB-231 breast cancer cells to anti-tumour effects of tumour necrosis factor- $\alpha, \mathrm{CH} 11$ and CYC202," Endocrine-Related Cancer, vol. 14, no. 2, pp. 305-315, 2007.

[50] F. Yin, D. Bruemmer, F. Blaschke, W. A. Hsueh, R. E. Law, and A. J. van Herle, "Signaling pathways involved in induction of GADD45 gene expression and apoptosis by troglitazone in human MCF-7 breast carcinoma cells," Oncogene, vol. 23, no. 26, pp. 4614-4623, 2004.

[51] M. Pignatelli, C. Cocca, A. Santos, and A. Perez-Castillo, "Enhancement of BRCA1 gene expression by the peroxisome proliferator-activated receptor $\gamma$ in the MCF-7 breast cancer cell line," Oncogene, vol. 22, no. 35, pp. 5446-5450, 2003.

[52] J. Pandhare, S. K. Cooper, and J. M. Phang, "Proline oxidase, a proapoptotic gene, is induced by troglitazone: evidence for both peroxisome proliferator-activated receptor $\gamma$-dependent and -independent mechanisms," Journal of Biological Chemistry, vol. 281, no. 4, pp. 2044-2052, 2006.

[53] D. Bonofiglio, S. Gabriele, S. Aquila, et al., "Peroxisome proliferator-activated receptor $\gamma$ activates fas ligand gene promoter inducing apoptosis in human breast cancer cells," Breast Cancer Research and Treatment. In press.

[54] H. Liu, C. Zang, M. H. Fenner, K. Possinger, and E. Elstner, "PPAR $y$ ligands and ATRA inhibit the invasion of human breast cancer cells in vitro," Breast Cancer Research and Treatment, vol. 79, no. 1, pp. 63-74, 2003.

[55] G. Magenta, X. Borenstein, R. Rolando, and M. A. Jasnis, "Rosiglitazone inhibits metastasis development of a murine mammary tumor cell line LMM3," BMC Cancer, vol. 8, article 47, pp. 1-10, 2008.

[56] B.-S. Herbert, V. P. Pearce, L. S. Hynan, et al., "A peroxisome proliferator-activated receptor- $\gamma$ agonist and the $\mathrm{p} 53$ rescue drug CP-31398 inhibit the spontaneous immortalization of breast epithelial cells," Cancer Research, vol. 63, no. 8, pp. 1914-1919, 2003.

[57] F. Chen, M. Wang, J. P. O'Connor, M. He, T. Tripathi, and L. E. Harrison, "Phosphorylation of PPAR $\gamma$ via active ERK1/2 leads to its physical association with p65 and inhibition of NF- $\kappa \beta$," Journal of Cellular Biochemistry, vol. 90, no. 4, pp. 732-744, 2003.

[58] G. Pascual, A. L. Fong, S. Ogawa, et al., "A SUMOylationdependent pathway mediates transrepression of inflammatory response genes by PPAR- $\gamma$," Nature, vol. 437, no. 7059, pp. 759-763, 2005.

[59] J. Lecomte, S. Flament, S. Salamone, et al., "Disruption of $\operatorname{ER} \alpha$ signalling pathway by PPAR $\gamma$ agonists: evidences of PPAR $\gamma$-independent events in two hormone-dependent breast cancer cell lines," Breast Cancer Research and Treatment. In press.

[60] J. Kirchheiner, I. Roots, M. Goldammer, B. Rosenkranz, and J. Brockmöller, "Effect of genetic polymorphisms in cytochrome P450 (CYP) 2C9 and CYP2C8 on the pharmacokinetics of oral antidiabetic drugs: clinical relevance," Clinical Pharmacokinetics, vol. 44, no. 12, pp. 1209-1225, 2005.

[61] L. L. H. Peeters, J.-L. Vigne, M. K. Tee, D. Zhao, L. L. Waite, and R. N. Taylor, "PPAR $\gamma$ represses VEGF expression in human endometrial cells: implications for uterine angiogenesis," Angiogenesis, vol. 8, no. 4, pp. 373-379, 2006.

[62] Y.-G. Fu, J. J. Y. Sung, K.-C. Wu, et al., "Inhibition of gastric cancer cells associated angiogenesis by $15 \mathrm{~d}$-prostaglandin $\mathrm{J}_{2}$ through the downregulation of angiopoietin-1," Cancer Letters, vol. 243, no. 2, pp. 246-254, 2006.

[63] K. Chu, S.-T. Lee, J.-S. Koo, et al., "Peroxisome proliferatoractivated receptor- $\gamma$-agonist, rosiglitazone, promotes angiogenesis after focal cerebral ischemia," Brain Research, vol. 1093, no. 1, pp. 208-218, 2006.

[64] F. Pistrosch, K. Herbrig, U. Oelschlaegel, et al., "PPAR $\gamma$ agonist rosiglitazone increases number and migratory activity of cultured endothelial progenitor cells," Atherosclerosis, vol. 183, no. 1, pp. 163-167, 2005.

[65] L. Meng, J. Zhou, H. Sasano, T. Suzuki, K. M. Zeitoun, and S. E. Bulun, "Tumor necrosis factor $\alpha$ and interleukin 11 secreted by malignant breast epithelial cells inhibit adipocyte differentiation by selectively down-regulating CCAAT/enhancer binding protein $\alpha$ and peroxisome proliferator-activated receptor $\gamma$ : mechanism of desmoplastic reaction," Cancer Research, vol. 61, no. 5, pp. 2250-2255, 2001. 
[66] P. Micke and A. Ostman, "Tumour-stroma interaction: cancer-associated fibroblasts as novel targets in anti-cancer therapy?" Lung Cancer, vol. 45, supplement 2, pp. S163-S175, 2004.

[67] H. A. Burgess, L. E. Daugherty, T. H. Thatcher, et al., "PPAR $\gamma$ agonists inhibit TGF- $\beta$ induced pulmonary myofibroblast differentiation and collagen production: implications for therapy of lung fibrosis," American Journal of Physiology, vol. 288, no. 6, pp. L1146-L1153, 2005.

[68] L. Sun, "Tumor-suppressive and promoting function of transforming growth factor $\beta$," Frontiers in Bioscience, vol. 9, pp. 1925-1935, 2004.

[69] B. Tang, M. Vu, T. Booker, et al., "TGF- $\beta$ switches from tumor suppressor to prometastatic factor in a model of breast cancer progression," The Journal of Clinical Investigation, vol. 112, no. 7, pp. 1116-1124, 2003.

[70] J. R. Benson, "Role of transforming growth factor $\beta$ in breast carcinogenesis," The Lancet Oncology, vol. 5, no. 4, pp. 229239, 2004.

[71] M. Lindberg and A. Astrup, "The role of glitazones in management of type 2 diabetes. A dream or a nightmare?" Obesity Reviews, vol. 8, no. 5, pp. 381-384, 2007.

[72] J. Wilding, "Thiazolidinediones, insulin resistance and obesity: finding a balance," International Journal of Clinical Practice, vol. 60, no. 10, pp. 1272-1280, 2006.

[73] L. U. Rosenberg, K. Einarsdóttir, E. I. Friman, et al., "Risk factors for hormone receptor-defined breast cancer in postmenopausal women," Cancer Epidemiology Biomarkers and Prevention, vol. 15, no. 12, pp. 2482-2488, 2006.

[74] H. S. Feigelson, A. V. Patel, L. R. Teras, T. Gansler, M. J. Thun, and E. E. Calle, "Adult weight gain and histopathologic characteristics of breast cancer among postmenopausal women," Cancer, vol. 107, no. 1, pp. 12-21, 2006.

[75] Y. Yin, R. G. Russell, L. E. Dettin, et al., "Peroxisome proliferator-activated receptor $\delta$ and $\gamma$ agonists differentially alter tumor differentiation and progression during mammary carcinogenesis," Cancer Research, vol. 65, no. 9, pp. 3950-3957, 2005.

[76] N. Suh, Y. Wang, C. R. Williams, et al., "A new ligand for the peroxisome proliferator-activated receptor- $\gamma$ (PPAR$\gamma$ ), GW7845, inhibits rat mammary carcinogenesis," Cancer Research, vol. 59, no. 22, pp. 5671-5673, 1999.

[77] R. G. Mehta, E. Williamson, M. K. Patel, and H. P. Koeffler, "A ligand of peroxisome proliferator-activated receptor $\gamma$, retinoids, and prevention of preneoplastic mammary lesions," Journal of the National Cancer Institute, vol. 92, no. 5, pp. 418-423, 2000.

[78] L. D. Yee, D. C. Young, T. J. Rosol, A. M. VanBuskirk, and S. K. Clinton, "Dietary (n-3) polyunsaturated fatty acids inhibit HER-2/neu-induced breast cancer in mice independently of the PPAR $\gamma$ ligand rosiglitazone," The Journal of Nutrition, vol. 135, no. 5, pp. 983-988, 2005.

[79] J. E. Green, K. Desai, Y. Ye, C. Kavanaugh, A. Calvo, and J.I. Huh, "Genomic approaches to understanding mammary tumor progression in transgenic mice and responses to therapy," Clinical Cancer Research, vol. 10, no. 1, pp. 385S390S, 2004.

[80] C. Koro, S. Barrett, and N. Qizilbash, "Cancer risks in thiazolidinedione users compared to other anti-diabetic agents," Pharmacoepidemiology and Drug Safety, vol. 16, no. 5, pp. 485-492, 2007.

[81] M. E. Ramos-Nino, C. D. MacLean, and B. Littenberg, "Association between cancer prevalence and use of thiazo- lidinediones: results from the Vermont Diabetes Information System," BMC Medicine, vol. 5, article 17, pp. 1-7, 2007.

[82] J. A. Dormandy, B. Charbonnel, D. J. Eckland, et al., "Secondary prevention of macrovascular events in patients with type 2 diabetes in the PROactive Study (PROspective pioglitAzone Clinical Trial in macroVascular Events): a randomised controlled trial," The Lancet, vol. 366, no. 9493, pp. 1279-1289, 2005.

[83] H. J. Burstein, G. D. Demetri, E. Mueller, P. Sarraf, B. M. Spiegelman, and E. P. Winer, "Use of the peroxisome proliferator-activated receptor (PPAR) $\gamma$ ligand troglitazone as treatment for refractory breast cancer: a phase II study," Breast Cancer Research and Treatment, vol. 79, no. 3, pp. 391397, 2003.

[84] M. E. Grossmann, K. J. Nkhata, N. K. Mizuno, A. Ray, and M. P. Cleary, "Effects of adiponectin on breast cancer cell growth and signaling," British Journal of Cancer, vol. 98, no. 2, pp. 370-379, 2008.

[85] L. Vona-Davis, M. Howard-McNatt, and D. P. Rose, "Adiposity, type 2 diabetes and the metabolic syndrome in breast cancer," Obesity Reviews, vol. 8, no. 5, pp. 395-408, 2007.

[86] A. Sapone, J. M. Peters, S. Sakai, et al., "The human peroxisome proliferator-activated receptor $\alpha$ gene: identification and functional characterization of two natural allelic variants," Pharmacogenetics, vol. 10, no. 4, pp. 321-333, 2000.

[87] C. Fiévet, J.-C. Fruchart, and B. Staels, "PPAR $\alpha$ and PPAR $\gamma$ dual agonists for the treatment of type 2 diabetes and the metabolic syndrome," Current Opinion in Pharmacology, vol. 6, no. 6, pp. 606-614, 2006.

[88] J. M. Peters, R. C. Cattley, and F. J. Gonzalez, "Role of PPAR $\alpha$ in the mechanism of action of the nongenotoxic carcinogen and peroxisome proliferator Wy-14,643," Carcinogenesis, vol. 18, no. 11, pp. 2029-2033, 1997.

[89] S. C. Hasmall, N. H. James, N. Macdonald, F. J. Gonzalez, J. M. Peters, and R. A. Roberts, "Suppression of mouse hepatocyte apoptosis by peroxisome proliferators: role of PPAR $\alpha$ and TNF $\alpha$," Mutation Research, vol. 448, no. 2, pp. 193-200, 2000.

[90] Q. Yang, T. Nagano, Y. Shah, C. Cheung, S. Ito, and F. J. Gonzalez, "The PPAR $\alpha$-humanized mouse: a model to investigate species differences in liver toxicity mediated by PPAR $\alpha, "$ Toxicological Sciences, vol. 101, no. 1, pp. 132-139, 2008.

[91] M. Maggiora, M. Bologna, M. P. Cerù, et al., "An overview of the effect of linoleic and conjugated-linoleic acids on the growth of several human tumor cell lines," International Journal of Cancer, vol. 112, no. 6, pp. 909-919, 2004.

[92] P. Thuillier, G. J. Anchiraico, K. P. Nickel, et al., "Activators of peroxisome proliferator-activated receptor- $\alpha$ partially inhibit mouse skin tumor promotion," Molecular Carcinogenesis, vol. 29, no. 3, pp. 134-142, 2000.

[93] D. Panigrahy, A. Kaipainen, S. Huang, et al., "PPAR $\alpha$ agonist fenofibrate suppresses tumor growth through direct and indirect angiogenesis inhibition," Proceedings of the National Academy of Sciences of the United States of America, vol. 105, no. 3, pp. 985-990, 2008.

[94] A. Pozzi, M. R. Ibanez, A. E. Gatica, et al., "Peroxisomal proliferator-activated receptor- $\alpha$-dependent inhibition of endothelial cell proliferation and tumorigenesis," Journal of Biological Chemistry, vol. 282, no. 24, pp. 17685-17695, 2007.

[95] K. M. Suchanek, F. J. May, J. A. Robinson, et al., "Peroxisome proliferator-activated receptor $\alpha$ in the human breast cancer 
cell lines MCF-7 and MDA-MB-231," Molecular Carcinogenesis, vol. 34, no. 4, pp. 165-171, 2002.

[96] C. Bocca, F. Bozzo, G. Martinasso, R. A. Canuto, and A. Miglietta, "Involvement of PPAR $\alpha$ in the growth inhibitory effect of arachidonic acid on breast cancer cells," British Journal of Nutrition, vol. 1, pp. 1-12, 2008.

[97] H. M. Faddy, J. A. Robinson, W. J. Lee, N. A. Holman, G. R. Monteith, and S. J. Roberts-Thomson, "Peroxisome proliferator-activated receptor $\alpha$ expression is regulated by estrogen receptor $\alpha$ and modulates the response of MCF-7 cells to sodium butyrate," International Journal of Biochemistry \& Cell Biology, vol. 38, no. 2, pp. 255-266, 2006.

[98] Y. Shi, M. Hon, and R. M. Evans, "The peroxisome proliferator-activated receptor $\delta$, an integrator of transcriptional repression and nuclear receptor signaling," Proceedings of the National Academy of Sciences of the United States of America, vol. 99, no. 5, pp. 2613-2618, 2002.

[99] H. E. Xu, M. H. Lambert, V. G. Montana, et al., "Molecular recognition of fatty acids by peroxisome proliferator- activated receptors," Molecular Cell, vol. 3, no. 3, pp. 397-403, 1999.

[100] U. Risérus, D. Sprecher, T. Johnson, et al., "Activation of peroxisome proliferator-activated receptor (PPAR) $\delta$ promotes reversal of multiple metabolic abnormalities, reduces oxidative stress, and increases fatty acid oxidation in moderately obese men," Diabetes, vol. 57, no. 2, pp. 332-339, 2008.

[101] P. Pelton, "GW-501516 GlaxoSmithKline/Ligand," Current Opinion in Investigational Drugs, vol. 7, no. 4, pp. 360-370, 2006.

[102] D. L. Sprecher, "Lipids, lipoproteins, and peroxisome proliferator activated receptor- $\delta$," The American Journal of Cardiology, vol. 100, no. 11, supplement 1, pp. S20-S24, 2007.

[103] R. L. Stephen, M. C. U. Gustafsson, M. Jarvis, et al., "Activation of peroxisome proliferator-activated receptor $\delta$ stimulates the proliferation of human breast and prostate cancer cell lines," Cancer Research, vol. 64, no. 9, pp. 31623170, 2004.

[104] C. J. Fabian, "Breast cancer chemoprevention: beyond tamoxifen," Breast Cancer Research, vol. 3, no. 2, pp. 99-103, 2001.

[105] V. G. Vogel, J. P. Costantino, D. L. Wickerham, et al., "Effects of tamoxifen vs raloxifene on the risk of developing invasive breast cancer and other disease outcomes: the NSABP Study of Tamoxifen and Raloxifene (STAR) P-2 trial," Journal of the American Medical Association, vol. 295, no. 23, pp. 27272741, 2006. 


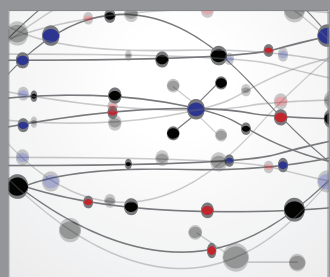

The Scientific World Journal
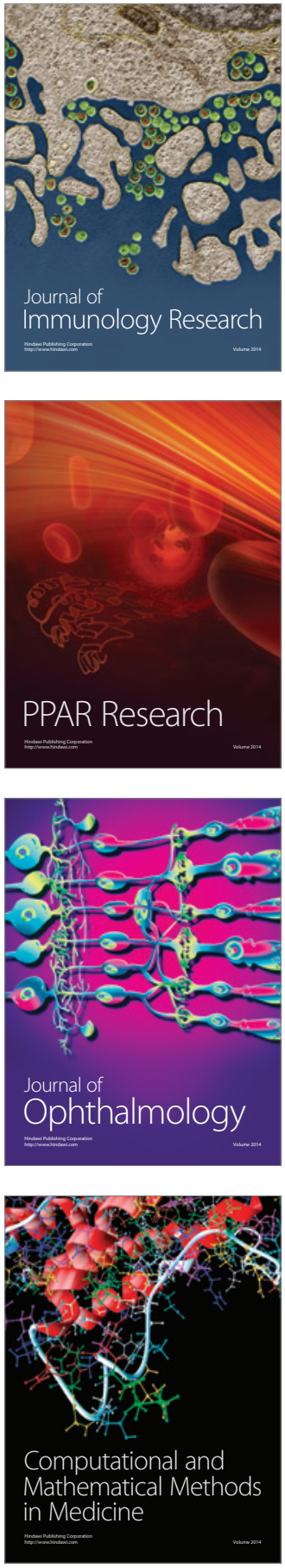

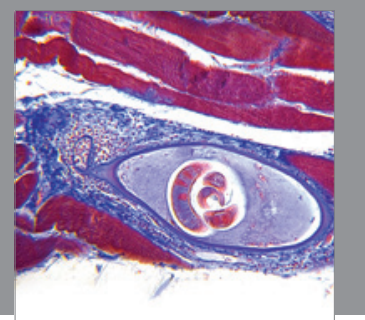

Gastroenterology

Research and Practice
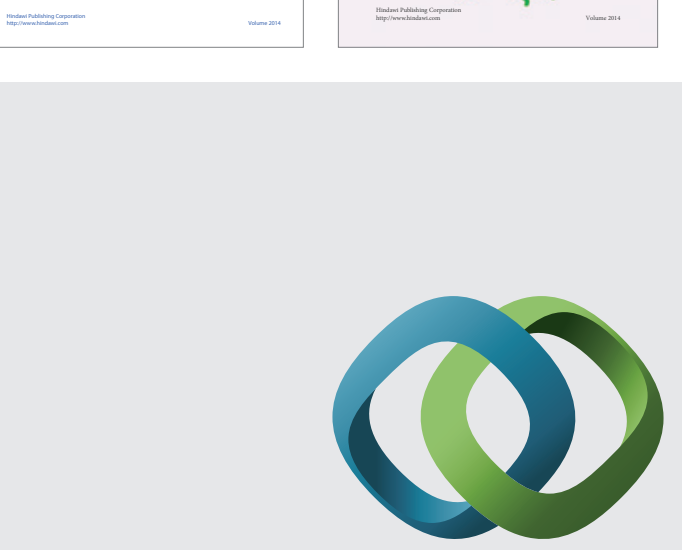

\section{Hindawi}

Submit your manuscripts at

http://www.hindawi.com
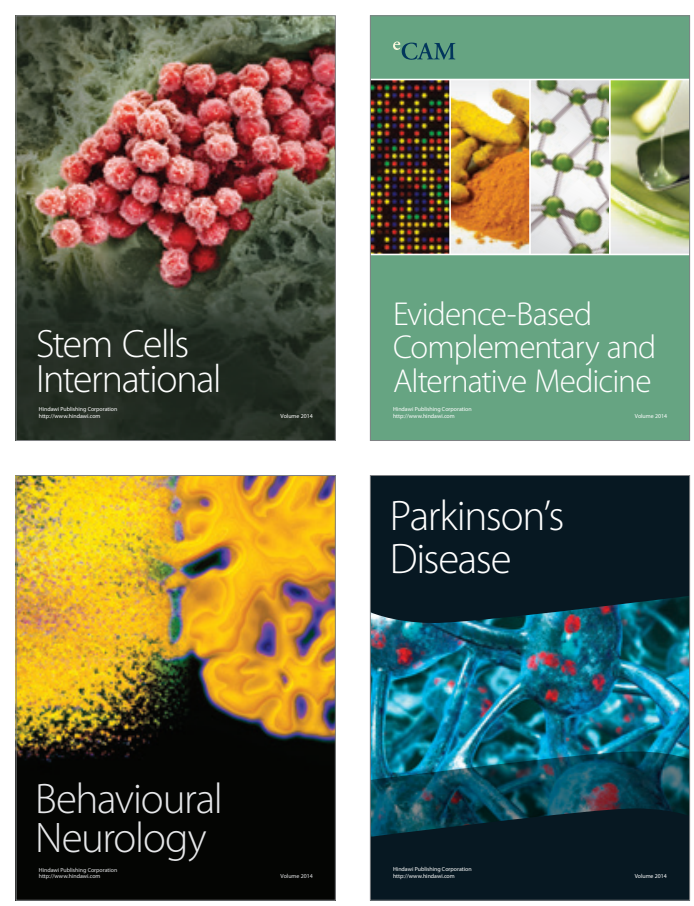

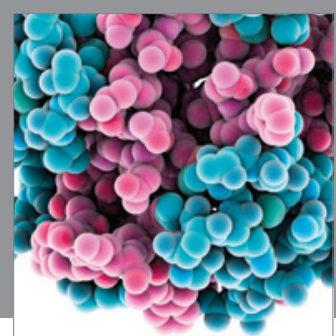

Journal of
Diabetes Research

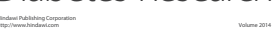

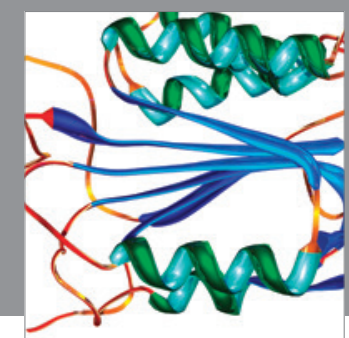

Disease Markers
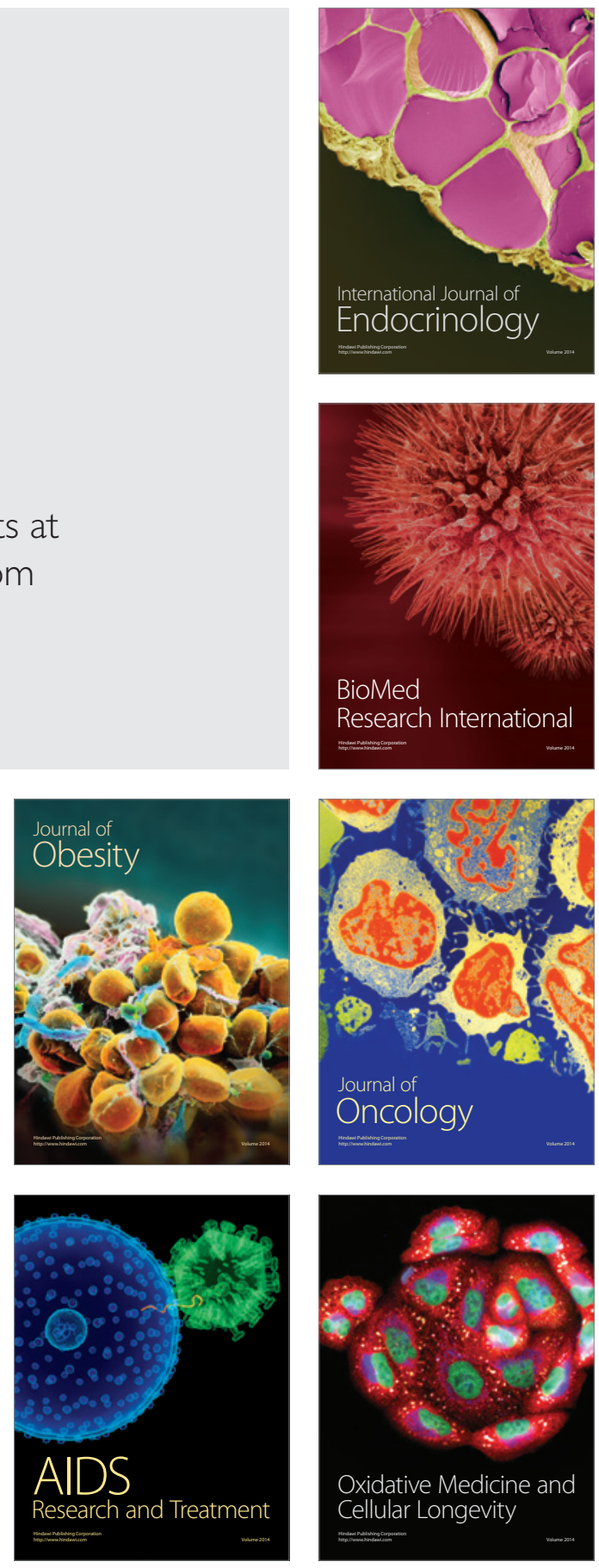